\title{
EXPRESSÃO DO p53 NO CARCINOMA EPIDERMÓIDE DO LÁBIO
}

\author{
P53 EXPRESSION IN SQUAMOUS CELL CARCINOMA OF THE LIP
}

\author{
Décio de Natale Caly ${ }^{1}$; Ethel Zimberg Cheter²; Abrão Rapoport, ECBC-SP'; \\ Humberto Torloni ${ }^{4}$; Sueli Nonogaki
}

\begin{abstract}
RESUMO: Objetivo. Verificar o valor da expressão do p53 no carcinoma epidermóide (CEC) de lábio. Método. O estudo imunohistoquímico foi feito em material fixo em formol e mantido em bloco de parafina, corado com anticorpos anti-p53, segundo técnica da Streptavidina-Biotina-Peroxidase. Para análise estatística, foi empregado o teste de Fisher para a diferenciação de grupos em relação às variáveis do estudo. Resultados. A expressão do p53 foi positiva em $87,5 \%$ do CEC bem diferenciado, $60 \%$ no moderadamente diferenciado e $91,67 \%$ no pouco diferenciado. Nas margens de ressecção cirúrgica foi negativa em $94,23 \%$ e positiva em $5,77 \%$, havendo associação entre o grau de diferenciação e a expressão do p53 ( $\mathrm{p}=0,05)$. Conclusão. A expressão do p53 foi positiva na lesão primária e negativa na margem de ressecção cirúrgica, mas não é determinante de mudanças no paradigma cirúrgico (Rev. Col. Bras. Cir. 2007; 34(2): 92-97).
\end{abstract}

Descritores: Genes p53; Lábio; Neoplasias labiais; Carcinoma de células escamosas.

\section{INTRODUÇÃO}

As neoplasias malignas da cabeça e do pescoço correspondem a $5 \%$ de todas as neoplasias em geral, e no Brasil, as estimativas do Instituto Nacional de Câncer (2003) ${ }^{1}$ colocam o câncer de cavidade oral na $6^{\mathrm{a}}$ localização na população masculina, e na $7^{\mathrm{a}}$ na população feminina.

O câncer de lábio ocorre na linha de junção entre a cavidade oral e a pele, tornando os dados aferidos no câncer de lábio geralmente confusos, pela dificuldade na determinação do sitio de origem da neoplasia ${ }^{2}$.

No Brasil, as taxas de incidência em São Paulo são 3,8 por 100.000 habitantes para homens e de 1,0 por 100.000 para mulheres ${ }^{3-6}$ e em Goiânia, de 2,2 por 100.000 por ano ${ }^{2}$. Dados do Registro Hospitalar de Câncer da Fundação Oncocentro de São $\mathrm{Paulo}^{7}$, demonstram que o câncer de lábio e da cavidade oral aparecem em quarto lugar dos casos de câncer nos homens com 12,1\% e em sexto lugar nos casos de câncer nas mulheres com 2,5\%.

O gene p53 faz parte dos chamados genes supressores de tumores tendo importante função sobre o controle do ciclo celular e apoptose. Alterações nesse gene são freqüentemente encontradas nas neoplasias malignas ${ }^{8}$ por suprimir o crescimento celular de células tumorais ${ }^{9,10}$ e o aumento da concentração do p53 selvagem está associado à parada do ciclo celular ${ }^{11}$ e morte celular programada (apoptose) $)^{12}$. Considerando que, a recidiva loco-regional é a principal causa de falha no tratamento do carcinoma epidermóide de cabeça e pescoço, foram propostos que mé- todos convencionais de estudo da margem cirúrgica não eram suficientes como fator preditivo de risco de recidiva da doença ${ }^{13}$. Após avaliar 24 casos de carcinoma epidermóide de cavidade oral, em material de blocos de parafina, $58 \%$ dos pacientes tinham pelo menos uma das margens positivas para marcação do p53, incluindo 8 de 10 pacientes que tiveram recorrência local da doença.

A expressão do p53 foi estudada em lesões de mucosa oral com evidências de lesões displásicas em 41 casos, dos quais, 35 (85\%) apresentavam expressão para o p53, concluindo que este achado não poderia ser usado como fator preditivo de doença ${ }^{14}$.

De uma maneira geral, a maioria dos estudos indica um envolvimento do gene supressor de tumor p53 como o processo de carcinogênese nos casos dos carcinomas epidermóides da cavidade oral. A análise das margens cirúrgicas foi referida em poucos trabalhos, sendo que na maioria deles, não houve tentativa de correlação entre as alterações moleculares da margem com a possibilidade de recidiva ou falha de tratamento. Assim, procuramos determinar a expressão do p53 no câncer do lábio e na margem de ressecção cirúrgica.

\section{MÉTODO}

Trata-se de um estudo retrospectivo, aberto, seqüencial em pacientes com câncer de lábio, de 1984 a 1996, no Departamento de Cabeça e Pescoço e Otorrinolaringologia do Hospital Heliópolis, São Paulo. Como fatores de inclusão

1. Mestre em Ciências da Saúde e Anátomo-Patologista do Hospital Heliópolis, Hosphel, São Paulo.

2. Chefe do Departamento de Gastroenterologia do Hospital Heliópolis, Hosphel, São Paulo.

3. Cirurgião do Departamento de Cirurgia de Cabeça e Pescoço e Otorrinolaringologia do Hospital Heliópolis, Hosphel, São Paulo.

4. Diretor do Instituto Ludwig de Pesquisa sobre o Câncer.

5. Bióloga do Instituto Ludwig de Pesquisa sobre o Câncer.

Recebido em 11/08/2006

Aceito para publicação em 22/10/2006

Conflito de interesses: nenhum

Fonte de financiamento: nenhuma

Trabalho realizado no Departamento de Cirurgia de Cabeça e Pescoço Otorrinolaringologia do Hospital Heliópolis, Hosphel, São Paulo. 
foram considerados os seguintes critérios: diagnóstico histológico de carcinoma epidermóide de lábio, pacientes não operados previamente e pacientes sem radioterapia prévia. A análise dos prontuários incluiu levantamento de dados epidemiológicos gerais( idade, sexo, raça) e a classificação das lesões do lábio conforme sua aparência clínica (ulcerada, úlcero-infiltrativa,úlcero-vegetante, úlcero-destrutiva, vegetante, tipos diversos).

Nos casos selecionados foram separados os blocos de parafina do tumor e das margens. Estes blocos foram recortados, recorados e lidos pela coloração de rotina (hematoxilina e eosina), conforme técnica padrão. A seguir, foram analisados em microscópio ótico, sendo avaliado em campos de pequeno, médio e grande aumento (40, 100, 250 e 400X). Foram utilizados como critérios de análise a graduação histológica ${ }^{15}$, tipo de crescimento tumoral, profundidade de invasão, margens cirúrgicas e distância da lesão e a margem.

Foi realizada análise imuno-histoquímica em material fixado em formol e mantido em blocos de parafina, corado com anticorpos anti-p53, segundo a técnica Streptavidina-BiotinaPeroxidase (SABC-“Streptavidin-Biotin-Complex") com recuperação antigênica pelo método da panela de pressão utilizando como anticorpo primário Mouse monoclonal proteina anti humana p53 clone DO-7 (Dako A/S, Denmark, código M7001) diluído em título pré-estabelecido de 1:100. A avaliação imunohistoquímica foi feita ao microscópio ótico, em médio e grande aumento (250 e 400X). A expressão da proteína p53 foi investigada no núcleo das células, sendo considerado como resultado positivo a coloração acastanhada no núcleo. A expressão da reação imuno-histoquímica foi avaliada tanto no tumor quanto na margem de ressecção cirúrgica.

A análise da reação foi feita por método semi-quantitativo, sendo adotado um critério de proporcionalidade da expressão da reação nas células neoplásicas. Utilizou-se a aplicação de testes não paramétricos, levando em consideração a natureza das distribuições e o nível de significância fixado em $10 \%(\mathrm{p}<0,10)$. Para as variáveis nominais, considerou-se a média, desvio padrão, mediana e valores mínimo e máximo. Nas variáveis nominais, calculou-se as porcentagens e freqüências relativas. O teste de Fischer foi utilizado para determinar a diferenciação de grupos em relação à determinada variável.

\section{RESULTADOS}

A idade dos pacientes variou entre 32 a 93 anos, com média de 61,02 anos, mediana de 61 anos. O sexo masculino apresentou freqüência absoluta de 42 pacientes $(79,25 \%)$ e o sexo feminino de $11(20,75 \%)$. Com relação à etnia, 51 pacientes $(96,23 \%)$ eram da raça branca, um $(1,89 \%)$ da raça negra e um $(1,89 \%)$ da raça amarela.

Quanto ao tempo de queixa nove (16,98\%) apresentavam história até três meses, $14(26,52 \%)$ entre 3 e 6 meses e $30(56,60 \%)$ acima de seis meses.

Vinte e sete pacientes $(50,94 \%)$ foram estadiados como $\mathrm{T} 1,15$ pacientes $(28,30 \%)$ como $\mathrm{T} 2$, sete pacientes $(13,21 \%)$ como T3 e quatro pacientes $(7,55 \%)$ como T4. O acometimento linfonodal foi considerado N0 em $92,31 \%$ dos casos, N1 em $5,77 \%$ e N2 em $1,92 \%$ dos pacientes.
Os resultados do grau de diferenciação mostram o CEC bem diferenciado (30,19\%), moderadamente diferenciado $(30,19 \%)$, moderadamente diferenciado $(47,17 \%)$ e pouco diferenciado(22,64\%).

Com relação à profundidade, $1,89 \%$ dos casos foram de tumor "in situ", 90,57\% apresentavam invasão muscular. $3,77 \%$ invasão da mucosa e 3,77\% com invasão da submucosa".

A distância entre o tumor e a margem de ressecção cirúrgica, variou de 2 a 13 milímetros, com média de 5,83 milímetros, todas livres de comprometimento neoplásico (Figura 1).

No estudo das margens de ressecção cirúrgica para detectar a expressão da proteína p53, esta foi negativa em 49 casos $(94,23 \%)$ e positiva em três casos $(5,77 \%)$, sendo que a intensidade de coloração da reação nos casos positivos foi de moderada intensidade em todos os três casos.

Foram feitas as correlações entre: grau de diferenciação histológica do tumor e a expressão da proteína p53 no tumor; grau de diferenciação e o percentual de expressão da proteína p53; grau de diferenciação e a intensidade da reação. Utilizou-se o teste exato de Fischer, cujos resultados encontram-se respectivamente representados nas Tabelas 1, 2 e 3 . Na tabela 1, afere-se que a expressão do p53 e o grau de diferenciação é marginalmente significativo $(\mathrm{p}=0,0553)$ quanto à expressão do gene na neoplasia do lábio. Quanto a relação entre o percentual de expressão do p53 e o grau diferenciação (Tabela 2), ocorreu associação não significante $(\mathrm{p}=0,0794)$. Finalmente, não houve relação de significância (Tabela 3) entre o grau de diferenciação e a intensidade da expressão do p53.

\section{DISCUSSÃO}

Os critérios anátomo-patológicos estudados nesta amostra, evidenciaram predominância do carcinoma moderadamente diferenciado $(47,17 \%)$, com crescimento expansivo. (47,17\%), com profundidade até a camada muscular (90,57\%).

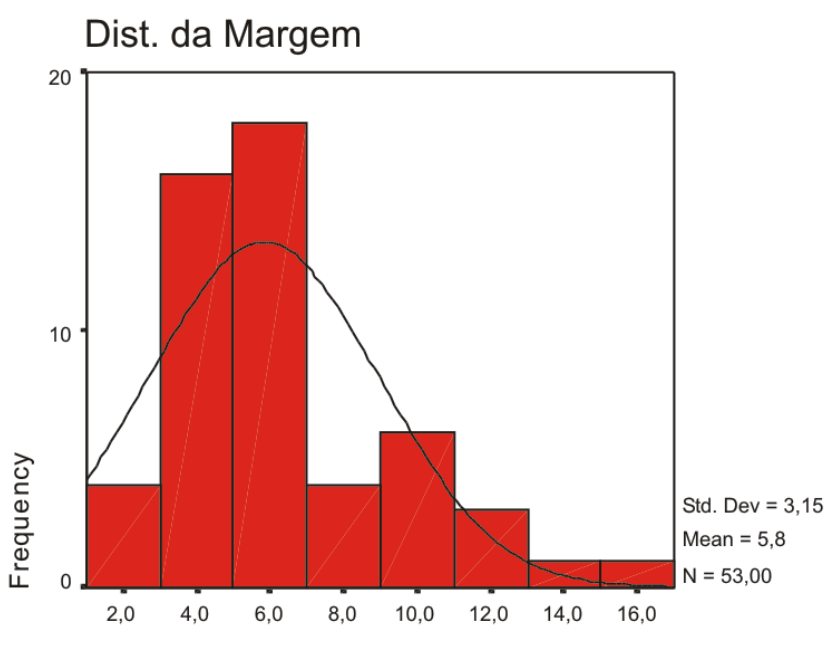

Dist. da Margem

Figura 1 - Histograma representando a variação da distância da margem do tumor em milimetros. 
Tabela 1 - Associação entre a expressão da p53 e o grau de diferenciação da neoplasia.

\begin{tabular}{|c|c|c|c|c|}
\hline \multirow[b]{2}{*}{ Grau de Diferenciação } & & \multicolumn{2}{|l|}{ P53 } & \multirow[b]{2}{*}{ Total } \\
\hline & & Não & Sim & \\
\hline \multirow[t]{4}{*}{ Bem diferenciado } & Casos & 2 & 14 & 16 \\
\hline & \% de Grau de Diferenciação & 12,50 & 87,50 & 100,00 \\
\hline & $\%$ de P53 & 15,38 & 35,00 & 30,19 \\
\hline & $\%$ de Total & 3,77 & 26,42 & 30,19 \\
\hline \multirow[t]{4}{*}{ Moderadamente diferenciado } & Casos & 10 & 15 & 25 \\
\hline & \% de Grau de Diferenciação & 40,00 & 60,00 & 100,00 \\
\hline & $\%$ de P53 & 76,92 & 37,50 & 47,17 \\
\hline & $\%$ de Total & 18,87 & 28,30 & 47,17 \\
\hline \multirow[t]{4}{*}{ Pouco diferenciado } & Casos & 1 & 11 & 12 \\
\hline & \% de Grau de Diferenciação & 8,33 & 91,67 & 100,00 \\
\hline & $\%$ de P53 & 7,69 & 27,50 & 22,64 \\
\hline & $\%$ de Total & 1,89 & 20,75 & 22,64 \\
\hline \multirow[t]{4}{*}{ Total } & Casos & 13 & 40 & 53 \\
\hline & \% de Grau de Diferenciação & 24,53 & 75,47 & 100,00 \\
\hline & $\%$ de P53 & 100,00 & 100,00 & 100,00 \\
\hline & $\%$ de Total & 24,53 & 75,47 & 100,00 \\
\hline
\end{tabular}

Teste Exato de Fisher $\quad$-value $=0,0553$

Casos Válidos 53

Conclusão: Existe associação marginalmente significante entre grau de diferenciação e a expressão da p53 na neoplasia.

Comparado com dados da literatura, nossa amostra apresenta ligeira discrepância, visto que em alguns trabalhos ${ }^{16,17}$ a predominância ocorreu para os cânceres bem diferenciados e com menor profundidade de invasão. Esta diferença pode relacionar-se com o diagnóstico mais tardio em nosso meio, gerando lesões maiores com maior invasão.
$\mathrm{Na}$ amostra estudada, as margens de ressecção tiveram média de 5,83 milímetros, apresentando em 41,50\% dos casos algum grau de displasia do epitélio e em 64,15\% dos casos lesões de dano solar, fato semelhante à literatura mundial ${ }^{16}$, que também relata margens cirúrgicas suficientes, porém com a presença de algum tipo de lesão na margem. Esses

Tabela 2 - Associação entre o percentual de expressão da proteína p53 e o grau de diferenciação da neoplasia.

\begin{tabular}{|c|c|c|c|c|c|c|c|c|}
\hline \multirow{2}{*}{\multicolumn{2}{|c|}{ Grau de Diferenciação }} & \multirow{3}{*}{$\frac{\mathbf{0}}{2}$} & \multirow{3}{*}{$\frac{10}{3}$} & \multirow{3}{*}{$\frac{25}{3}$} & \multirow{3}{*}{$\begin{array}{l}\mathbf{5 0} \\
3\end{array}$} & \multicolumn{2}{|c|}{ P53-Tumor (\%) } & \multirow[t]{2}{*}{ Total } \\
\hline & & & & & & 75 & 100 & \\
\hline \multirow[t]{4}{*}{ Bem diferenciado } & Casos & & & & & 5 & & 16 \\
\hline & \% Grau de Diferenciação & 12,50 & 18,75 & 18,75 & 18,75 & 31,25 & & 100,00 \\
\hline & $\%$ P53-Tumor & 15,38 & 75,00 & 75,00 & 23,08 & 29,41 & & 30,19 \\
\hline & $\%$ do Total & 3,77 & 5,66 & 5,66 & 5,66 & 9,43 & & 30,19 \\
\hline \multirow{4}{*}{$\begin{array}{l}\text { Moderadamente } \\
\text { diferenciado }\end{array}$} & Casos & 10 & 1 & & 5 & 8 & 1 & 25 \\
\hline & \% Grau de Diferenciação & 40,00 & 4,00 & & 20,00 & 32,00 & 4,00 & 100,00 \\
\hline & $\%$ P53-Tumor & 76,92 & 25,00 & & 38,46 & 47,06 & 50,00 & 47,17 \\
\hline & $\%$ do Total & 18,87 & 1,89 & & 9,43 & 15,09 & 1,89 & 47,17 \\
\hline \multirow[t]{4}{*}{ Pouco diferenciado } & Casos & 1 & & 1 & 5 & 4 & 1 & 12 \\
\hline & \% Grau de Diferenciação & 8,33 & & 8,33 & 41,67 & 33,33 & 8,33 & 100,00 \\
\hline & $\%$ P53-Tumor & 7,69 & & 25,00 & 38,46 & 23,53 & 50,00 & 22,64 \\
\hline & $\%$ do Total & 1,89 & & 1,89 & 9,43 & 7,55 & 1,89 & 22,64 \\
\hline \multirow[t]{4}{*}{ Total } & Casos & 13 & 4 & 4 & 13 & 17 & 2 & 53 \\
\hline & \% Grau de Diferenciação & 24,53 & 7,55 & 7,55 & 24,53 & 32,08 & 3,77 & 100,00 \\
\hline & $\%$ P53-Tumor & 100,00 & 100,00 & 100,00 & 100,00 & 100,00 & 100,00 & 100,00 \\
\hline & $\%$ do Total & 24,53 & 7,55 & 7,55 & 24,53 & 32,08 & 3,77 & 100,00 \\
\hline
\end{tabular}

Teste Exato de Fisher

$p$-value $=0,0794$

Conclusão: Não ocorreu associação significante entre grau de diferenciação e o percentual de expressão da proteína p53 no tumor. 
Tabela 3 - Associação entre a intensidade da reação da p53 e o grau de diferenciação. Distribuição de Grau de Diferenciação por Intensidade P53-Tumor.

\begin{tabular}{|c|c|c|c|c|c|c|c|}
\hline \multirow{2}{*}{ Grau de Diferenciação } & & \multirow[b]{2}{*}{$\mathbf{0 , 0 0}$} & \multirow[b]{2}{*}{1,00} & \multicolumn{3}{|c|}{ Intens. P53-tumor } & \multirow[t]{2}{*}{ Total } \\
\hline & & & & 2,00 & 3,00 & 4,00 & \\
\hline \multirow[t]{4}{*}{ Bem diferenciado } & Casos & 2 & 4 & 7 & 3 & & 16 \\
\hline & \% Grau de Diferenciação & 12,50 & 25,00 & 43,75 & 18,75 & & 100,00 \\
\hline & $\%$ Intens. P53-tumor & 15,38 & 30,77 & 41,18 & 37,50 & & 30,19 \\
\hline & $\%$ do Total & 3,77 & 7,55 & 13,21 & 5,66 & & 30,19 \\
\hline \multirow[t]{4}{*}{ Moderadamente diferenciado } & Casos & 10 & 4 & 7 & 3 & 1 & 25 \\
\hline & \% Grau de Diferenciação & 40,00 & 16,00 & 28,00 & 12,00 & 4,00 & 100,00 \\
\hline & $\%$ Intens. P53-tumor & 76,92 & 30,77 & 41,18 & 37,50 & 50,00 & 47,17 \\
\hline & $\%$ do Total & 18,87 & 7,55 & 13,21 & 5,66 & 1,89 & 47,17 \\
\hline \multirow[t]{4}{*}{ Pouco diferenciado } & Casos & 1 & 5 & 3 & 2 & 1 & 12 \\
\hline & \% Grau de Diferenciação & 8,33 & 41,67 & 25,00 & 16,67 & 8,33 & 100,00 \\
\hline & $\%$ Intens. P53-tumor & 7,69 & 38,46 & 17,65 & 25,00 & 50,00 & 22,64 \\
\hline & $\%$ do Total & 1,89 & 9,43 & 5,66 & 3,77 & 1,89 & 22,64 \\
\hline \multirow[t]{4}{*}{ Total } & Casos & 13 & 13 & 17 & 8 & 2 & 53 \\
\hline & \% Grau de Diferenciação & 24,53 & 24,53 & 32,08 & 15,09 & 3,77 & 100,00 \\
\hline & $\%$ Intens. P53-tumor & 100,00 & 100,00 & 100,00 & 100,00 & 100,00 & 100,00 \\
\hline & $\%$ do Total & 24,53 & 24,53 & 32,08 & 15,09 & 3,77 & 100,00 \\
\hline
\end{tabular}

Teste Exato de Fisher $\quad$-value $=0,289$

Casos Válidos - 53

Conclusão: Não há evidências de associação entre grau de diferenciação da neoplasia e a intensidade da reação do p53.

resultados podem indicar a facilidade na ressecção ampla da lesão, permitindo assim maior segurança ao tratamento efetuado, porém a presença de lesões na margem de ressecção cirúrgica serve como um alerta para o seguimento destes pacientes.

Neste estudo o valor encontrado da freqüência absoluta da expressão da proteína p53 na neoplasia foi de $75,47 \%$ (Tabela 3), índice este que vai de encontro com a revisão de literatura mundial ${ }^{18}$. Também ressaltamos que, feita a correlação entre o grau de diferenciação histológico, da neoplasia e a expressão da proteína p53, houve uma associação significativa entre as neoplasias com menor grau de diferenciação histológica com a maior expressão da proteína p53. Da mesma maneira, quando feita a associação do grau de diferenciação histológica com os percentuais de positividade da reação, houve o mesmo tipo de associação, onde as neoplasias com menor grau de diferenciação apresentavam proporção maior na expressão da reação imuno-histoquímica. A intensidade da reação imuno-histoquímica não apresentou correlação significativa.

Ao demonstrarmos a expressão da proteína p53 no tecido neoplásico, comprovamos que existe uma mutação do gene p53, a qual se relaciona com o processo de carcinogênese do câncer de lábio. Devemos ainda lembrar que, a mutação do gene p53 é apenas um dos vários fatores implicados na carcinogênese do câncer de lábio. Porém, o valor obtido neste estudo ressalta a importância deste gene, reafirmando os dados da literatura mundial ${ }^{19,20}$ que relacionam o papel do p53 sobre a carcinogênese dos cânceres de cabeça e pescoço.

Os resultados obtidos entre a associação da positividade da expressão da neoplasia com o menor grau de diferenciação histológica pode ser um indício que lesões me- nos diferenciadas poderiam estar relacionadas com maiores alterações genéticas nesta população neoplásica e talvez, associar-se com comportamento mais agressivo da doença. Entretanto, para propor tal hipótese é necessário que outras correlações sejam estudadas, como as associações entre a expressão do p53 nos cânceres menos diferenciados com as taxas de recidiva e mortalidade.

No que diz respeito ao CEC de lábio, esta neoplasia é acentuadamente diferenciada e de evolução clínica lenta, fato este corroborada pela presença do p53 em percentuais baixo. Isto explica parcialmente a razão da baixa incidência de recidiva primária da lesão, metastatização submento-mandibular pouco freqüente e cura habitual da doença nos estádios I, II e III.

Ao estudar a expressão da proteína p53 na mucosa adjacente ao tumor (mucosa da margem de ressecção cirúrgica), o índice que encontramos nesse estudo foi de 94,23\% dos casos negativo para a expressão da proteína p53 e 5,77\% positivo. Na literatura mundial ${ }^{18-23}$, os índices de positividade do epitélio adjacente na mucosa da cavidade oral são bastante variáveis, evidenciando que a mucosa adjacente à neoplasia sem características de atipias citológicas normal ou displásica apresentava-se negativa para a expressão da proteína p53. O índice encontrado neste estudo da expressão da proteína p53 na margem de ressecção cirúrgica foi de $5,77 \%$, valor que contradiz alguns autores ${ }^{13,21-23}$. Porém, se considerarmos também na análise deste fato, que ao estudar a margem de ressecção cirúrgica pela coloração de rotina (hematoxilina e eosina), estas margens apresentaram-se livres de neoplasia (valor mínimo entre a margem e a neoplasia à distância de dois milímetros), podemos inferir que esta mucosa estando livre histologicamente, também encontrar-se-á livre do ponto de vista molecular. Considerando a margem de ressecção cirúrgi- 
ca como parâmetro de mucosa normal e como campo de cancerização, a ação dos mesmos agentes carcinogênicos deveriam influenciar esta mucosa e conseqüentemente, deveria haver expressão da proteína p53 neste epitélio. Contudo, apesar de, ao avaliarmos esta mucosa termos encontrado na maioria dos casos resposta ao dano solar $(64,15 \%$ dos casos com elastose solar) e um variado grau de atipia nesta mucosa (41,50\%), a ausência de expressão da proteína p53 indicaria que o efeito de uma mutação gênica neste epitélio adjacente ainda possa não ter ocorrido ${ }^{24}$. Conseqüentemente, apesar desta mucosa já ter sida exposta a um fator de risco e indutor de carcinogênese, as outras etapas do processo de carcinogênese ainda não se processaram neste epitélio adjacente $^{25}$. Portanto, apesar desta mucosa já apresentar algum tipo de dano, este ainda não está se manifestando como uma lesão que irá progredir para uma malignização. Podemos ainda sugerir que, apesar do dano celular já existir pela ação dos agentes carcinogênicos, o gene p53 ainda não estaria mutado, e, portanto, mantendo sua ação como um gene de controle da proliferação e diferenciação celular. A ausência da sua expressão na mucosa adjacente, mesmo na presença de outras lesões nesta mucosa, indicaria ainda a integridade deste gene e do seu produto de ação, a proteína p53. Pode corroborar esta hipótese o fato do câncer de lábio apresentar prognóstico e comportamento biológico diferente em relação aos outros cânceres da cabeça e do pescoço.

Em termos gerais, os carcinomas de lábio apresentam bom prognóstico quando tratados adequadamente, apre- sentando baixos índices de recidiva quando as margens de ressecção cirúrgica são adequadamente ressecadas, fato contrário às demais neoplasias de cabeça e pescoço, onde o índice de recidiva é maior. Desta maneira, a não expressão da proteína p53 na mucosa adjacente da margem de ressecção indicaria que, este epitélio ainda não possui alterações suficientes para iniciar sua transformação maligna, apesar de em alguns casos já ter alterações histológicas, como as alterações por dano solar e displasias leves ${ }^{26}$. Levando em consideração ter a mucosa algum grau de alteração, não deve ser esquecido que esta mucosa já se apresenta com danos, que a possibilidade de mutação do gene já existe, podendo a expressão da proteína p53 ser apenas uma questão de tempo e de exposição aos fatores carcinogênicos ${ }^{27}$. $\mathrm{O}$ fato de termos encontrado um expressivo resultado ao demonstrar a expressão da proteína p53 no tumor, inferimos que a técnica imunohistoquímica foi eficaz e que a avaliação da mucosa da margem foi realmente negativa na maioria dos casos, e deste modo podemos excluir a possibilidade de falha técnica na avaliação da amostra. Todavia, vale lembrar que o emprego dos métodos imuno-histoquímicos deva ser um recurso apenas complementar no planejamento terapêutico do CEC de lábio, visto que as características clínicas da neoplasia, sua lenta evolução e baixo grau de metastatização e recidiva permitem afirmar que as alterações genéticas (p53 é uma delas) não é determinante do curso evolutivo da doença e sua positividade não altera o planejamento terapêutico/cirúrgico e ou radioterápico habitual.

\begin{abstract}
Background: To assess the p53 expression in squamous cell carcinoma (SCC) of the lip. Methods: Immunohystochemical study for samples fixed in formaline and paraphin in bloc stained with anti-p53 antibodies through Streptavidina-BiotinaPeroxidase. For statistical analysis the Fisher Test was employed for group differences $(p<0.10)$. Results: The p53 expression were positive in $87.50 \%$ of well differentiated SCC, $60.0 \%$ of moderately differentiated tumors, $91.67 \%$ of poorly differentiated; for surgical margins, $94.23 \%$ were negative and $5.77 \%$ positive, with an association between differentiation degree and $p 53$ expression ( $p=0.05$ ). Conclusion: The p53 expression was significant in SCC of the lip and negative for surgical margins, but it is not determinant of changing in surgical paradigm.
\end{abstract}

Key-words: Genes, p53; Lip; Lip neoplasms; Carcinoma, squamous cell.

\section{REFERÊNCIAS}

1. Instituto Nacional de Câncer. Disponível em http:// www.inca.org.br/estimativa/2003/mapa.asp?D=9;2003.

2. Moore S, Johnson N, Pierce A, Wilson D. The epidemiology of lip cancer: a review of global incidence and aetiology. Oral Dis. 1999; 5(3):185-95.

3. Chen J, Katz RV, Krutchkoff DJ, Eisenberg E. Lip cancer. Incidence trends in Connecticut, 1935-1985. Cancer. 1992; 70(8):2025-30.

4. Cox B, Taylor K, Treasure E. Trends in oral cancer by subsite in New Zealand. Eur J Cancer B Oral Oncol. 1995; 31B(2):113-7.

5. Ostman J, Anneroth G, Gustafsson H, Travelin B. Malignant oral tumors in Sweden 1960-1989: an epidemiological study. Eur J Cancer B Oral Oncol. 1995; 31B(2):106-12.

6. Mirra AP, Franco EL. Incidência de câncer no município de São Paulo, Brasil; Ludwig Institute for Cancer Research Epidemiology a Monographs, São Paulo Séries- 1, 1985.
7. Fundação Oncocentro São Paulo. Disponível em http:// www.fosp.saude.sp.gov.br./html/bol_207.html, 2002.

8. Hollstein M, Sidransky D, Vogelstein B, Harris CC. p53 mutations in human cancers. Science. 1991;253(5015):49-53.

9. Baker SJ, Markowitz S, Fearon ER, Willson JK, Vogelstein B. Suppression of human colorectal carcinoma cell growth by wild type p53. Science. 1990; 249(4971):912-5.

10. Srivastava S, Zou ZQ, Pirollo K, Bllattner W, Chiang EH. Germ-line transmission of a mutated p53 gene in a cancerprone family with Li-Fraumeni syndrome. Nature. 1990;348(6303):747-9.

11. Kastan MB, Onyekwere O, Sidransky D, Vogelstein B, Craig RW. Participation of 553 protein in the cellular response to DNA damage. Cancer Res. 1991;51(23 Pt 1):6304-11.

12. Shaw PH. The role of p53 in cell cycle regulation. Pathol Res Pract. 1996;192(7):669-75.

13. Ball VA, Righi PD, Tejada E, Radpour S, Pavelic ZP, Gluckman JL. p53 immunostaining of surgical margins as a predictor of 
local recurrence in squamous cell carcinoma of the oral cavity and oropharynx. Ear Nose Throat J. 1997;76(11):818-23.

14. Rich AM, Kerdpon D, Reade PC. p53 expression in oral precancer and cancer. Aust Dent J. 1999;44(2):103-5.

15. Broders AC. Squamous cell epithelioma of the lip: a study of live hundred and thirty-seven cases. JAMA. 1920;74:656-64.

16. de Visscher JG, Schaapveld M, Otter R, Visser O, van der Waal I. Epidemiology of cancer of the lip in the Netherlands. Oral Oncol. 1998;34(5):421-6.

17. Daniele E, Rodolico V, Leonardi V, Tralongo V. Prognosis in lower lip squamous cell carcinoma: assessment of tumor factors. Pathol Res Pract. 1998;194(5):319-24.

18. Gusterson BA, Anbazhagan R, Warren W, Midgely C, Lane DP, O'Hare M, Stamps A, Carter R, Jayatilake H. Expression of p53 in premalignant and malignant squamous epithelium. Oncogene. 1991;6(10):1785-9.

19. Shin DM, Kim J, Ro JY, Hittelman J, Roth JA, Hong WK, Hittelman WN. Activation of 553 gene expression in premalignant lesions during head and neck tumorigenesis. Cancer Res. 1994;54(2):321-6.

20. Piffko J, Bankfalvi A, Ofner D, Berens A, Tkotz T, Joos U, Bocker W, Schmid KW. Expression of p53 protein in oral squamous cell carcinomas and adjacent non-tumorous mucosa of the floor of they mouth: an archival immunohistochemical study using wet autoclave pretreatment for antigen retrieval. J Oral Pathol Med. 1995;24(8):337-42.

21. Gallo O, Bianchi S. p53 expression: a potential biomarker for risk of multiple primary malignancies in the upper aerodigestive tract. Eur J Cancer B Oral Oncol. 1995;31B(1)53-7.

22. Rowley H, Helliwell TR, Jones AS, Roland NJ, Field EA, Field $\mathrm{JK}$. An immunohistochemical analysis of $\mathrm{p} 53$ protein expression in pre-malignant and malignant tissues of the oral cavity. Clin Otolaryngol. 1997;22(1):23-9.
23. Cruz IB, Meijer CJ, Snijders PJ, Snow GB, Walboomers JM, van der Waal I. p53 immunoexpression in non-malignant oral mucosa adjacent to oral squamous cell carcinoma: potential consequences for clinical management. J Pathol. 2000;191(2): 132-7.

24. Garcia-Montesinos-Perea B, Val-Bernal JF, Saiz-Bustillo R. Epidermoid carcinoma of the lip: an immunohistochemical study. Med Oral Patol Oral Cir Bucal. 2005;10(5):454-61.

25. Neto Pimentel DR, Michalany N, Alchorne M, Abreu M, Borra RC, Weckx L. Actinic cheilitis: histopathology and p53. J Cutan Pathol. 2006;33(8):539-44.

26. Horta MC, Assis LA, Souza PF, Araújo VC, Gomez RS, Aguiar MC. p53 and p21WAF1/CIP1 overexpression at the invasive front of lower lip squamous cell carcinoma. J Pathol Med. 2007;36(2):88-92.

27. Siegelmann D, Ben Zhack O, Hanlow A, Ridge JA, Stein ME, Khan Del Wal V, Langer CJ. P53 alteration in oral tongue cancer is not significantly associated with age at diagnosis or tobacco exposure. Tumori. 2005;91:346-50.

Como citar este artigo:

Caly DN, Cheter EZ, Rapoport A, Torloni H, Nonogaki S. Expressão do p53 no carcinoma epidermóide do lábio. Rev Col Bras Cir. [periódico na Internet] 2007; 34(2). Disponível em URL: http:// www.scelo.br/rcbc

Endereço para correspondência:

Abrão Rapoport

Rua Iramaia, 136 - Jardim Europa

01450-020 - São Paulo - SP

E-mail: arapoport@terra.com.br 